\title{
EVALUATION OF POSTURAL BALANCE IN THIRD TRIMESTER PREGNANCY
}

\author{
Radhika K. Shingala *1, Manali Desai ${ }^{2}$, Priyanka Honkalas ${ }^{3}$, Ajay Kumar ${ }^{4}$. \\ ${ }^{* 1}$ Graduate, DPO's Nett College of Physiotherapy, Thane, India. \\ ${ }^{2}$ Assistant Professor, DPO's Nett College of Physiotherapy, Thane, India. \\ ${ }^{3}$ Assistant Professor, DPO's Nett College of Physiotherapy, Thane, India. \\ ${ }^{4}$ Principal, DPO's Nett College of Physiotherapy, Thane, India.
}

\section{ABSTRACT}

Background: Pregnancy is a state of various physiological and anatomical changes in a female's body. The increasing body weight leads to the shift in COG and increase in abdominal contents leading to reduced stability and increased use of visual cues which occur in pregnant females as pregnancy advances. Several physiological responses to pregnancy diminish the body's ability to maintain adequate balance, and place the women at a higher risk of injury and falls. Thus assessment for postural stability is very important to prevent such complications.

Objective: To evaluate postural balance in third trimester pregnant females using Four square step test.

Materials and methodology: Study was cross sectional observational study. Data was collected by convenient sampling method 60 Healthy women, 30 pregnant and 30 non-pregnant, of age group 20-30 years were selected. Evaluation of postural stability was done using 4 square step test (FSST). The mean of two time trial (in seconds) was noted. The data was collected and analysed using paired t-test.

Results: There was statistically significant difference in mean time taken to complete the test between pregnant group and non-pregnant group. $(p<0.05)$

Conclusion: Thus, our study showed that pregnant females took longer time to complete the postural balance test. KEY WORDS: Four square step test, pregnant females, postural balance, stability, third trimester, fall risk.

Address for correspondence: Radhika K. Shingala, Graduate, DPO's Nett College of Physiotherapy, Thane, India. Phone No: 8879486844, 8169442935 E-Mail: rkshingala91@gmail.com

Access this Article online

Quick Response code

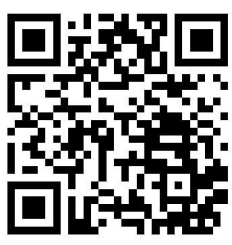

DOI: $10.16965 /$ ijpr.2019.113

Journal Information

International Journal of Physiotherapy and Research

ICV for 2016 ISSN (E) 2321-1822 | ISSN (P) 2321-8975

https://www.ijmhr.org/ijpr.html

DOI-Prefix: https://dx.doi.org/10.16965/ijpr

\section{Article Information}

Received: 22 Feb 2019

Peer Review: 22 Feb 2019

Revised: None
Accepted: 01 Apr 2019

Published (O): 20 Jun 2019

Published (P): 11 Aug 2019

\section{BACKGROUND}

Pregnancy, also known as gestation, is the time during which one or more offspring develops inside a woman. The developmental stages of pregnancy are called trimesters or three-month periods, because of the distinct changes that occur in each stage.

Pregnancy is a state of great physical and emotional changes in a women's life. Several physiological, anatomical as well as hormonal changes are seen in the female body during pregnancy. Physiological changes occur in pregnancy to nurture the developing foetus and prepare the mother for labour and delivery. Some of these changes influence normal biochemical values while others may mimic symptoms of medical disease. It is important to differentiate between normal physiological changes and disease pathology [1]. 


\section{Changes due to pregnancy include-}

- Significant weight gain,

- Increased ligamentous laxity and spinal lordosis

- Decreased neuromuscular control and abdominal muscle strength,

- Altered biomechanics and

- An anterior shift in the location of the centre of mass [2].

Several physiological responses to pregnancy diminish the body's ability to maintain adequate balance, and place the women at a higher risk of injury and falls [2]. Increased risk of falling during pregnancy may be related to these anatomical, hormonal and physiological changes.

Centre of gravity is a place in the body where its mass is equally distributed [3]. Centre of force is the projection of the COG within the support base and it results from the reaction forces of the ground with the support; it is a neuromuscular response to shift in the COG [3]. The increase in the body mass and body size during pregnancy can shift the centre of gravity (COG), which slowly shifts up and forward as the uterus and baby grows, which also results in increase oscillation of the centre of force (COF). Because the body has no previous neuromuscular experience of its new evolving centre point, it is less adaptive to control balance resulting in unstable postural balance [3]. This alteration can increase the risk of falling, which occurs in $25 \%$ of pregnant women [4]. Thus, there is need to assess postural balance in third trimester pregnant females.

Balance can be assessed using many different Balance tests like Timed up and go test (TUG), Step test, Functional reach test (FRT) etc. Balance, being multifactorial in nature, has different aspects of measurement. One such aspect is the ability to step quickly in different directions [5-7] which is very necessary for performing the activities of daily living. The Four square step test (FSST) is a valid, reliable, easy to score, quick to administer, requires little space, and needs no special equipment. It has a sensitivity of $85 \%$, a specificity of $88 \%$ to $100 \%$, and a positive predictive value of $86 \%$. It has been found to have an excellent inter-rater (ICC-0.99) and retest reliability (ICC-0.98) [9]. Evidence for validity of the FSST was found through its strong co-relations with the TUG test and Step test.

The risk of fall during pregnancy is similar to the risk observed in elderly individuals [5]. As the pregnancy advances, that is towards the third trimester, the risk of falling increases [6]. Qualitatively expressing changes in balance during pregnancy compared to non-pregnant women may provide insight into fall prevention for pregnant women performing activities of daily living. Thus, the objective of our study was to determine Postural Balance in pregnant females using FSST.

\section{MATERIALS AND METHODOLOGY}

This was cross sectional observational study performed on 60 females, 30 pregnant and 30 non-pregnant (control group) aged $20-30$ years were selected randomly. The inclusion criteria being- Low risk pregnancy, Single foetus, Normal BMI females with pregnancy additional weight gain of 7-16 kg. Females having Fluctuations of symptoms during pregnancy, Obese pregnant females, Women suffering from pedal oedema, any complications of pregnancy (like pre-eclamsia, gestational diabetes), any musculoskeletal, psychological, neurological pathology were excluded from participating in the study. Materials used were 4 Canes (not more than $2.5 \mathrm{~cm}$ in diameter) and a stop-watch. The study was approved by Institutional Ethics Committee.

Method: A proper step wise procedure was followed for completion of the study. One maternity hospital was selected by lottery method to conduct the study. After selection of hospital subjects were selected on basis of inclusion and exclusion criteria. A written consent form was taken from the subject in the language best understood by them. The aim, need of study and methodology was explained to the subjects. Demonstration of technique was given to each subject. The subjects both feet must contact with the floor in each square and she has to face forward during the entire sequence. A chair was kept on both sides as a safety measure. The subject was asked to complete one practice trial to ensure they know the sequence. The sequence was demonstrated to the subject. 
Two FSST were completed with the mean time in seconds taken as the score [9]. Similar method was followed for the control group (Non Pregnant females). Two time trials were recorded and mean was calculated.

Fig (a): depicting outline of four square step test using cane. [14] Source: Roos MA et al. 2016 [14].

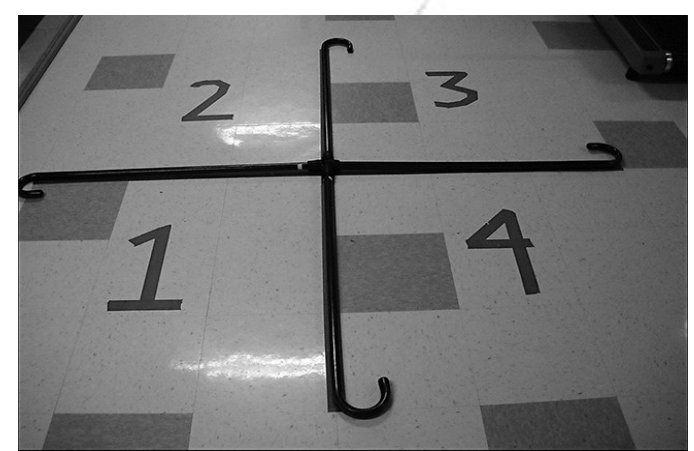

Fig (b): showing directions of movements in four square step test. https://wssuptgeriebp.wikispaces.com/ Four\%20Step\%20Square\%20Test

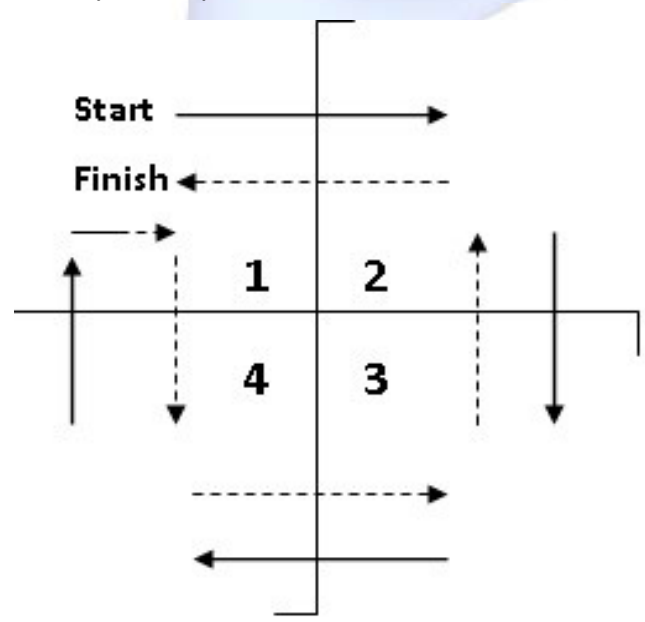

Statistical analysis: The data was initially tested for normal distribution using the one sample Kolmogorov Smirnov test for Normality. Since the data was normally distributed, parametric test was used. The mean time calculated for both the groups was statistically analysed using paired' $t$ ' test.

\section{RESULT}

The result of paired $t$ test shows that there was a statistically significant difference in time taken to complete the Four Square step test by pregnant females as compared to the control group $(p<0.05)$. The table 1 shows the difference in mean and standard deviation of time (seconds) taken by pregnant and Non pregnant females. It was seen that mean \pm SD for the pregnant females was $13.15 \pm 0.806$ and for control was $8.45 \pm 0.8212$ seconds in 60 subjects.
Table 1: Comparison of mean time trial of FOUR SQUARE STEP TEST for Pregnant v/s Non-pregnant control group.

\begin{tabular}{|c|c|c|c|}
\hline Groups & $\begin{array}{c}\text { Mean } \\
\text { (seconds) }\end{array}$ & $\begin{array}{c}\text { Standard } \\
\text { deviation }\end{array}$ & p-value \\
\hline $\begin{array}{c}\text { Non pregnant } \\
\text { (control group) }\end{array}$ & 8.45 & 0.8212 & \multirow{2}{*}{0.001 (significant) } \\
\hline Pregnant & 13.15 & 0.8068 & \\
\hline
\end{tabular}

${ }^{*} \mathrm{p}<0.05$

\section{DISCUSSION}

In the present study, 60 Healthy women, 30 pregnant and 30 non-pregnant, of age group 2030 years were selected. Evaluation of postural balance was done using 4 square step test (FSST). The mean of two time trial (in seconds) was noted. The data was collected and analysed using paired t-test.

Our study showed that pregnant females took longer time to complete the test suggesting that postural balance is affected compared to control group. The probable reason for increase in time taken can be the shift in COG due to weight gain and abdominal increase in pregnant women. Many literatures have reported that poor dynamic equilibrium is noted during third trimester of pregnancy. ${ }^{3}$ Also higher anteriorposterior oscillations found in third trimester pregnant females suggest decrease in postural balance in that phase [10].

John jang et al. in their study done on 30 women, 15 pregnant and 15 non pregnant done on balance and preferred stance width during pregnancy concluded that there is perceived degradation in balance during pregnancy which is strongly related to increase in postural sway instability in the anterior posterior direction [11]. Also, Butler EE et al. in their study on postural equilibrium during pregnancy, done on 12 pregnant women and different weeks of gestation, concluded that postural stability declines during pregnancy and remains diminished at 6 to 8 weeks after delivery. This study also indicated that there is an increase in reliance on visual cues to maintain balance which might have been one more reason for increase in time taken by pregnant females in our study as the four square step test demanded the subject to face forwards throughout the test [12].

Postural instability in pregnancy occurs due to numerous changes in woman's body during preg- 
-nancy. The hormonal, physiological as well as anatomical changes occuring during pregnancy result in decrease in abdominal muscle strength, increase in weight, increase ligamentous laxity and also spinal lordosis resulting in shift of COG more anteriorly, altering the postural balance and in turn increasing the risk of falls [13].

Clinical observation and empirical evidences indicate that postural balance decreases in pregnancy specifically during third trimester as compared to non-pregnant subjects of same age group. Surveys indicate that postural instability degrades more in later weeks of gestation i.e. third trimester due to the various anatomical changes as well as physiological changes.

The relation between postural instability and shift in COG is quiet clear and might be the most probable reason for the present study, but increase in requirement of visual cues to maintain balance and instructions of forward facing during four square step test also are clinically co-relating.

Also changes in gait pattern due to increased lordosis might serve as a reason for decreased postural balance in third trimester. Ultimately, we anticipate that postural balance in third trimester is reduced as compared to the non-pregnant control group.

\section{CONCLUSION}

Thus our study showed that there was significant decrease in postural balance in Third trimester as compared to non-pregnant females of the same age group due to increase in time taken to complete the Four Square Step Test (FSST).

Limitations: small sample size. Again, we did not consider exercising and non-exercising pregnant females separately. Females conceiving more than single foetus were also not included in the present study.

Clinical Implication: Four square step test can be used as a reliable, safe and valid objective tool for assessment of postural balance in pregnant females. Balance exercises can be added in the Ante-Natal program of pregnant females with proper assessment and supervision.

\section{ABBREVIATIONS:}

COG - Centre of gravity

FSST - Four Square Step test.

\section{Conflicts of interest: None}

\section{REFERENCES}

[1]. Priya Soma Pillai, University of Pretoria; Cardiovascular Journal of Africa, Volume 27, Issue 2, March 2016:89-94.

[2]. Ahmet Inanir et.al, Evaluation of postural equilibrium and fall risk during pregnancy, Gaziosmanpasa University School of Medicine, Turkey, 2014;11221125.

[3]. Ribas SI and Guirro ECO, Analysis of plantar pressure and postural balance during different phases of pregnancy, Rev. bras. fisioter., Sao Carlos, 2007;11(5):391-6.

[4]. Butler EE,Colon I, Druzin ML, Rose J. Postural equlibrium during pregnancy: Decreased stability with increased reliance on visual cues. Am J Obstet Gynecol. 2006; 195(4):1104-8.

[5]. Whitcome KK, Shapiro L, Lieberman DE. Fetal load and the evolution of lumbar lordosis in bipedal hominins. Nature 2007; 450:1075-8.

[6]. Dunning K, LeMasters G, Bhattachary A. A major public health issue: the high incidence of falls during pregnancy. Matern Child Health J 2010.

[7]. O'Loughlin JL, Robitaille Y, Boivin JF, Suissa S, Incidence of and risk factors for falls and injurious falls among community-dwelling elderly, Am J Epidemiol 1993;137:342-54.

[8]. Wayne Dite, BAppSci, Grad Dip, Viviene A, Temple, Phd. A clinical test of stepping and change of direction to identify multiple falling older adults; Arch physical medical rehabilitation. 2002;83.

[9]. Diet W, and Temple, V A. A clinical test of stepping and change of direction to identify multiple falling older adults. Arch Phys Med Rehabil 2002;83(11):1566-1571.

[10]. Bulent Cakmak et.al, Evaluation of postural equilibrium and fall risk during pregnancy, Gaziosmanpasa University School of Medicine, Turkey, 2014;1122-1125.

[11]. Jang J, Hsiao KT. Hsiao-Wecksler ET. Balance (perceived and actual) and preferred stance width during pregnancy. Clin Biomech (Bristol Avon) 2008;23:468-76.

[12]. Rose J et al. Postural equlibrium during pregnancy: Decreased stability with increased reliance on visual cues . Am J Obstet Gynecol. 2006;195(4):11048.

[13]. Margaret Polden and Jill Mantle. Physiotherapy in obstetrics and gynaecology. 1990. reprinted 2007:26-40.

[14]. Roos MA, Reisman DS, Hicks GE, Rose W, Rudolph KS. Development of the Modified Four Square Step Test and its reliability and validity in people with stroke. J Rehabil Res Dev. 2016;53(3):403-12. http:/ /dx.doi.org/10.1682/JRRD.2014.04.0112

How to cite this article: Radhika K. Shingala, Manali Desai, Priyanka Honkalas, Ajay Kumar. EVALUATION OF POSTURAL BALANCE IN THIRD TRIMESTER PREGNANCY. Int J Physiother Res 2019;7(4):3109-3112. DOI: 10.16965/ ijpr.2019.113 